\title{
Erratum to: Beam dynamics and stability analysis of an intense beam in a continuously twisted quadrupole focusing channel
}

The Publishers

EDP Sciences, Società Italiana di Fisica and Springer-Verlag

Original article: Eur. Phys. J. Plus (2016) 131: 393, DOI: 10.1140/epjp/i2016-16393-x

Received: 9 November 2016

Published online: 1 December 2016 - (C) Società Italiana di Fisica / Springer-Verlag 2016

Due to a technical problem, fig. 9 partly overlaps the last line of the caption to fig. 8 .

Find here below fig. 8 with its complete caption.

The Publishers regret this mistake and apologize for any inconvenience caused.
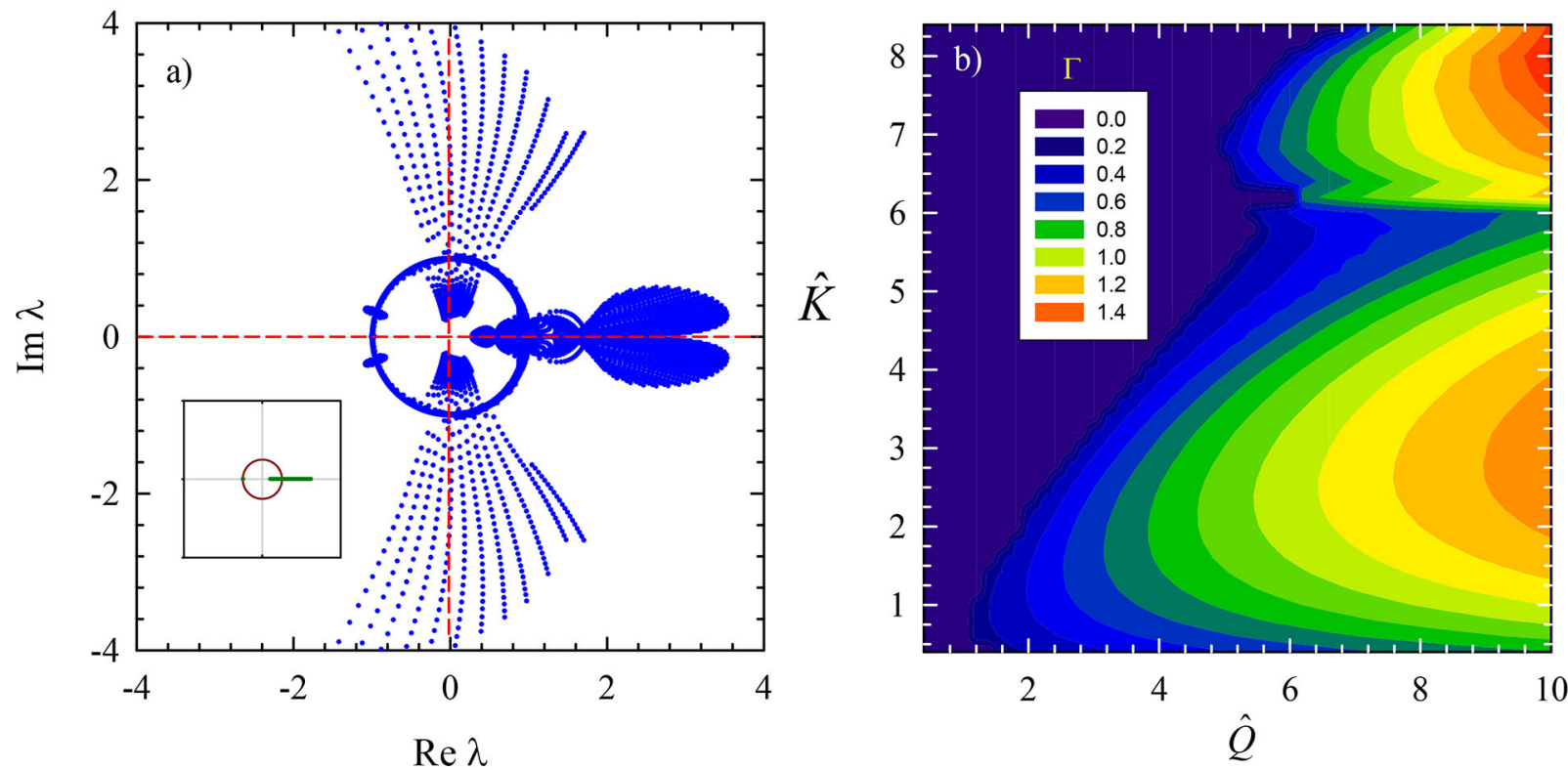

Fig. 8. Plots show the (a) eigenvalues of ten eigenmodes and (b) contour of the growth rate per period $\Gamma=\ln |\lambda|$ of the dominant mode in parameters regime $(\hat{Q} \in(0,10), \hat{K} \in(0.5,8.5))$ for a mismatched beam. This choice of parameters covers the entire range of $\chi \in(0,1)$, representing both emittance as well as space-charge-dominated beam. 